\title{
Outcome of ICU patients with Clostridium difficile infection
}

\author{
Jean-Ralph Zahar ${ }^{1,2}$, Carole Schwebel ${ }^{5}$, Christophe Adrie ${ }^{3}$, Maité Garrouste-Orgeas ${ }^{1,4}$, Adrien Français ${ }^{1}$, \\ Aurélien Vesin ${ }^{1}$, Molière Nguile-Makao ${ }^{1}$, Alexis Tabah ${ }^{1,5}$, Kevin Laupland $^{1,6}$, Alban Le-Monnier $^{7,8}$ and \\ Jean-François Timsit ${ }^{1,35^{*}}$, for the OUTCOMEREA study group
}

\begin{abstract}
Introduction: As data from Clostridium difficile infection (CDI) in intensive care unit (ICU) are still scarce, our objectives were to assess the morbidity and mortality of ICU-acquired CDI.

Methods: We compared patients with ICU-acquired CDI (watery or unformed stools occurring $\geq 72$ hours after ICU admission with a stool sample positive for C. difficile toxin A or B) with two groups of controls hospitalized at the same time in the same unit. The first control group comprised patients with ICU-acquired diarrhea occurring $\geq 72$ hours after ICU admission with a stool sample negative for $C$. difficile and for toxin A or B. The second group comprised patients without any diarrhea.

Results: Among 5,260 patients, 512 patients developed one episode of diarrhea. Among them, 69 (13.5\%) had a CDI; 10 (14.5\%) of them were community-acquired, contrasting with $12(17.4 \%)$ that were hospital-acquired and 47 (68\%) that were ICU-acquired. A pseudomembranous colitis was associated in 24/47 (51\%) ICU patients. The median delay between diagnosis and metronidazole administration was one day $\left(25^{\text {th }}\right.$ Quartile; $75^{\text {th }}$ Quartile $(0 ; 2)$ days). The case-fatality rate for patients with ICU-acquired CDI was 10/47 (21.5\%), as compared to 112/443 (25.3\%) for patients with negative tests. Neither the crude mortality (cause specific hazard ratio; CSHR $=0.70,95 \%$ confidence interval; $\mathrm{Cl} 0.36$ to $1.35, P=0.3$ ) nor the adjusted mortality to confounding variables (CSHR $=0.81,95 \%$ $\mathrm{Cl} 0.4$ to $1.64, P=0.6)$ were significantly different between CDI patients and diarrheic patients without CDI. Compared to the general ICU population, neither the crude mortality (SHR $=0.64,95 \% \mathrm{Cl} 0.34$ to $1.21, P=0.17$ ), nor the mortality adjusted to confounding variables (CSHR $=0.71,95 \%$ confidence interval (CI) 0.38 to $1.35, P=$ $0.3)$, were significantly different between the two groups. The estimated increase in the duration of stay due to CDI was 8.0 days \pm 9.3 days, $(P=0.4)$ in comparison to the diarrheic population, and 6.3 days $\pm 4.3(P=0.14)$ in comparison to the general ICU population.
\end{abstract}

Conclusions: If treated early, ICU-acquired CDI is not independently associated with an increased mortality and impacts marginally the ICU length of stay.

\section{Introduction}

Since 2000, multiple hospital-based Clostridium difficile infection (CDI) outbreaks have been described worldwide, and recent papers from North America have suggested an increased risk for in-hospital mortality [1,2]. However, these studies have provided conflicting results and the effects of hospital-acquired CDI on patients' outcomes

\footnotetext{
* Correspondence: jftimsit@chu-grenoble.fr

'INSERM U823; University Grenoble 1 - Albert Bonniot Institute, Rond-point de la Chantourne, Grenoble, 38042, France

Full list of author information is available at the end of the article
}

remain incompletely understood. The reported mortality rates associated with $C$. difficile vary, up to $83 \%$ in some studies $[3,4]$. Previous studies have been inconsistent in this observation $[5,6]$ and this may reflect different patient populations or limitations in study design, as several of these studies have failed to include a control group [7], or to include different infecting strains [1], or have not adjusted for confounding variables, such as severity of illness. Despite the fact that $C$. difficile is one of the most important causes of nosocomial infection in the intensive care unit (ICU), studies on CDI consequences are still
C Biomed Central

(C) 2012 Zahar et al.; licensee BioMed Central Ltd. This is an open access article distributed under the terms of the Creative Commons Attribution License (http://creativecommons.org/licenses/by/2.0), which permits unrestricted use, distribution, and reproduction in any medium, provided the original work is properly cited. 
rare. Among critically ill patients, CDI seems to be responsible for a $6 \%$ incremental increase in the risk of attributable mortality [8]. But it is difficult to determine the true attributable mortality for CDI in studies conducted on specific populations, such as the elderly or burn patients. As a result of the inherent severity of critical illness, the impact of acquisition of CDI may be expected to be greatest in ICU. Therefore, the objective of this study was to examine the influence of the development of CDI on the ICU patients' mortality.

\section{Materials and methods Study population}

The present study used data in an endemic setting from three medical and/or surgical centers of the multicenter prospective cohort OUTCOMEREATM, with homogeneous procedures for microbiological diagnosis of CDI. Patients were included between January 1999 and January 2009. ICU-acquired CDI was defined as watery or unformed stools, according to the Bristol stool chart [9], in a 24-hour period occurring $\geq 72$ hours after ICU admission with a laboratory confirmation of a stool sample positive for $C$. difficile toxin A or B by an immunoassay enzyme [10]. Two control groups were chosen, the first including patients hospitalized at the same time in the same unit with watery or unformed stools in a 24-hour period occurring $>72$ hours after ICU admission, but with a stool sample negative for $C$. difficile toxin A or B and a negative stool culture. The second one comprised patients hospitalized at the same time and the same unit. Pseudomembranous colitis was defined as the presence confirmed by endoscopy of typical plaque-like lesions of the pseudomembrane in patients with CDI as defined above.

All codes and definitions were established prior to the study initiation. All practitioners used the same definition before any testing. Moreover, the Quality of the Database was systematically controlled. The data-capture software automatically conducted multiple checks for internal consistency of most of the variables at entry in the database. Queries generated by these checks were resolved with the source ICU before any incorporation of the new data into the database. At each participating ICU, the data quality was controlled by having a senior physician from another participating ICU checking a $2 \%$ random sample of the study data. A one-day coding course is organized annually with the study investigators and clinical research organization monitors.

The following data were collected: admission characteristics - age, sex, and origin; body weight; diagnosis at ICU admission; admission category - main reason for ICU admission; chronic diseases; McCabe score; main clinical features; and treatments used, including antimicrobials. The following scores were computed at admission, then once a day: Simplified Acute Physiologic Score (SAPSII)
[11], Logistic Organ Dysfunction (LOD) [12,13], and Sequential Organ Failure Assessment (SOFA) [12,14]. Daily data about use of procedures, antibiotic consumption and proton-pump inhibitor were also collected. We recorded the durations of invasive mechanical ventilation, of the ICU and hospital stays, vital status at ICU and at hospital discharge. According to French law, this database study did not require informed consent.

\section{Statistical analysis}

Results are expressed as frequencies and percentages for categorical variables, and as medians and quartiles for continuous variables. Independent risk factors of ICUacquired CDI were identified using multivariate logistic regression (See Additional file 1). Patients were followed from ICU admission to the occurrence of one event, or censored at ICU discharge. Two different analyses were performed using either the overall population or only the patients with diarrhea and sampled for CDI.

In the overall population analysis, univariate risk factors of ICU death were detected using a Cause Specific Hazard model [15]. ICU admission was considered as time 0 . Death in the ICU was the variable of interest, whereas discharge alive from ICU was considered as a competing event with ICU death [16]. ICU-acquired CDI was included as a time-dependent variable, which equals to 0 before infection, and to 1 from the day of CDI until the end of the follow-up. Last, a Cause Specific Hazard model was conducted to assess the impact of CDI on prognosis, with adjustment on time-fixed and timedependent confounding factors, such as iatrogenic events occurring between admission and the CDI, bloodstream infection during ICU stay (BSI), ventilator-associated pneumonia (VAP), surgical site infection, pneumothorax during ICU stay, gastrointestinal bleeding during ICU stay, and severe hypernatremia $[17,18]$.

In the second analysis, we only used patients with diarrhea. The time of CDI test performance was considered as Day 0 , and CDI infection was considered as a time-fixed covariate. Other covariates were introduced in a Cause Specific Hazard model as previously described.

Results were presented with Cause Specific Hazard ratios (CSHRs) and 95\% confidence intervals (95\% CI). Models were stratified by center.

Finally, we estimated the prolongation of ICU stay using the disability model approach [19]. We used a multi-state model with four states, and all diarrheic populations started in an initial state. Then, prolongation of ICU stay was determined by reaching one of two competing absorbing states, (death or discharge alive), by taking into account the intermediate state (ICU-acquired CDI). Finally, we computed standard error estimation for prolongation of ICU stay thanks to the bootstrap method and 2,000 random samples with replacement and computed 
$P$-value using the Wald test. $P$-values $<0.05$ were considered significant. Statistical analysis was performed using SAS 9.1 (SAS Institute, Cary, NC, USA). Length of stay prolongation was calculated with $\mathrm{R}$ software ( $\mathrm{R}$ foundation, Vienna, Austria), using the change LOS library.

Assuming a $40 \%$ rate of hospital death in the diarrheic population, 471 patients were necessary to detect a hazard ratio (HR) of 2 for death with greater than $90 \%$ power and a type I error of 0.05 [20]. Similarly, 4,290 patients were necessary, assuming a 35\% rate of hospital death in the whole population.

\section{Ethical issues}

According to French law, this study did not require patient consent, as it involved research on a database. The study was approved by the institutional review board of the Centre d'Investigation Rhône-Alpes-Auvergne.

\section{Results}

From 5,260 patients collected in the three centers, 512 patients $(9.7 \%)$ underwent $C D$ toxin testing by enzymelinked immunosorbent assay on fecal samples for an episode of watery or unformed stools, of which $69(69 / 512=$ $13.5 \%)$ patients were positive. This corresponds to an incidence of ICU-acquired diarrhea of 0.97/1,000 patientsdays (Figure 1).

Among the 512 patients tested, 315 (61.5\%) were men, median age was 67 years $\left(1^{\text {st }}\right.$ and $3^{\text {rd }}$ Quartiles: 56 to 76 years) and the average SAPS and LOD were respectively $45\left(1^{\text {st }}\right.$ and $3^{\text {rd }}$ Quartiles: 36 to 59$)$ and $6\left(1^{\text {st }}\right.$ and $3^{\text {rd }}$ Quartiles: 4 to 8 ). At least one chronic illness was present in $226(44.1 \%)$ patients, and 128 (25\%) patients died during ICU stay (33.8\% during hospital stay). Characteristics of tested, ICU-acquired CDI patients, and non ICUacquired CDI patients are shown in Table 1.

The case group consisted of 47 (68\%) ICU-acquired CDI (incidence: $3.6 / 1,000$ patient-days). Of these patients with CDI, $24(51 \%)$ had a pseudomembranous colitis (incidence 1.84/1,000 patient-days). Among the $47 \mathrm{ICU}$ acquired CDI, the median time elapsed between ICU admission and first symptoms of CDI, was 8 (5 to 18) days. Three patients had septic shock at diagnosis and one required a surgical treatment. Thirty-one (66\%) patients received metronidazole as first line treatment, 15 (32\%) received vancomycin, and two patients received a combination therapy. Median time to initiate specific antibiotic therapy was one day $(0 ; 2)$ after stool sampling. Our epidemiological data and the absence of strains resistant to fluoroquinolones suggest that none of our isolates belonged to the epidemic clone O27. Characteristics of the 47 ICU-acquired CDI patients were described in Table 2. The rate of patients tested was homogeneous across centers (data not shown).

\section{Mortality}

The impact of CDI on mortality was homogeneous across centers (data not shown). ICU death in patients with CDI infection was associated with a high LOD score $(P=0.01)$, a high McCabe score $(P=0.02)$, and with immunosuppression $(P=0.02)$. Two different groups were used to analyze the impact of ICU-acquired CDI on patient's outcome. The first analysis compared patients discharged alive $(n=4,135)$ versus those dead $(n=1,125)$, and showed that CDI had no significant effect on mortality as a crude $(\mathrm{CSHR}=0.64,95 \% \mathrm{CI} 0.34$ to $1.21, P=0.17)$ or adjusted factor $($ CSHR $=0.71,95 \%$ CI 0.38 to $1.35, P=$ 0.3) (See Table 3).

The second analysis compared ICU-acquired CDI patients with diarrheic patients with negative stool culture: the crude effect of CDI on mortality was still not significant $(\mathrm{CSHR}=0.70,95 \% \mathrm{CI} 0.36$ to $1.35, P=0.3)$. Moreover, after adjustment on confounding factors and iatrogenic events between admission and occurrence of diarrhoea, the effect on mortality remained not significant $(\mathrm{CSHR}=0.81,95 \% \mathrm{CI} 0.40$ to $1.64, P=0.6)$ (See Table 4$)$.

Results remained similar when excluding patients with metronidazole (IV or oral) or vancomycin (oral) before the diagnostic test (adjusted CSHR $=0.84,95 \%$ CI 0.41 to $1.71, P=0.6$ ), or when only taking into account cases with pseudomembranous colitis acquired in ICU ( $n=24$ cases, CSHR $=0.80,95 \%$ CI 0.31 to $2.03, P=0.6$ ).

Results would only be slightly different if the 95/443 (21.4\%) given metronidazole or vancomycin within 48 hours following a negative test were excluded from the statistical analysis. (adjusted CSHR Death $=0.80(0.39$ to $1.65), P=0.5$, CSHR $_{\text {discharge }}=0.68$ (0.46 to 1.00$), P=$ $0.0475)$.

\section{Length of stay}

The median length of ICU stay in the whole population of diarrheic patients was 17 (8 to 34) days, whereas the median length of ICU stay in the CDI population was $20(12$ to 42) days. Using a multistate model, the estimated prolongation of ICU stay for the diarrheic population due to C. difficile was 8.0 days \pm 9.3 days, $P=0.4$.

Moreover, the median length of ICU stay in the whole population was 4 ( 3 to 9 ) days, whereas the median length of ICU stay in the ICU-acquired CDI group was 20 (12 to 42) days. The estimated prolongation of ICU stay due to $C$. difficile was 6.3 days $\pm 4.3, P=0.14$

\section{Discussion}

In our retrospective study conducted in an ICU cohort population, we found that ICU- and hospital crude mortality of CDI patients were 21 and 34\%, respectively. Despite a significantly higher crude mortality, when using modern statistical models, CDI was not associated 


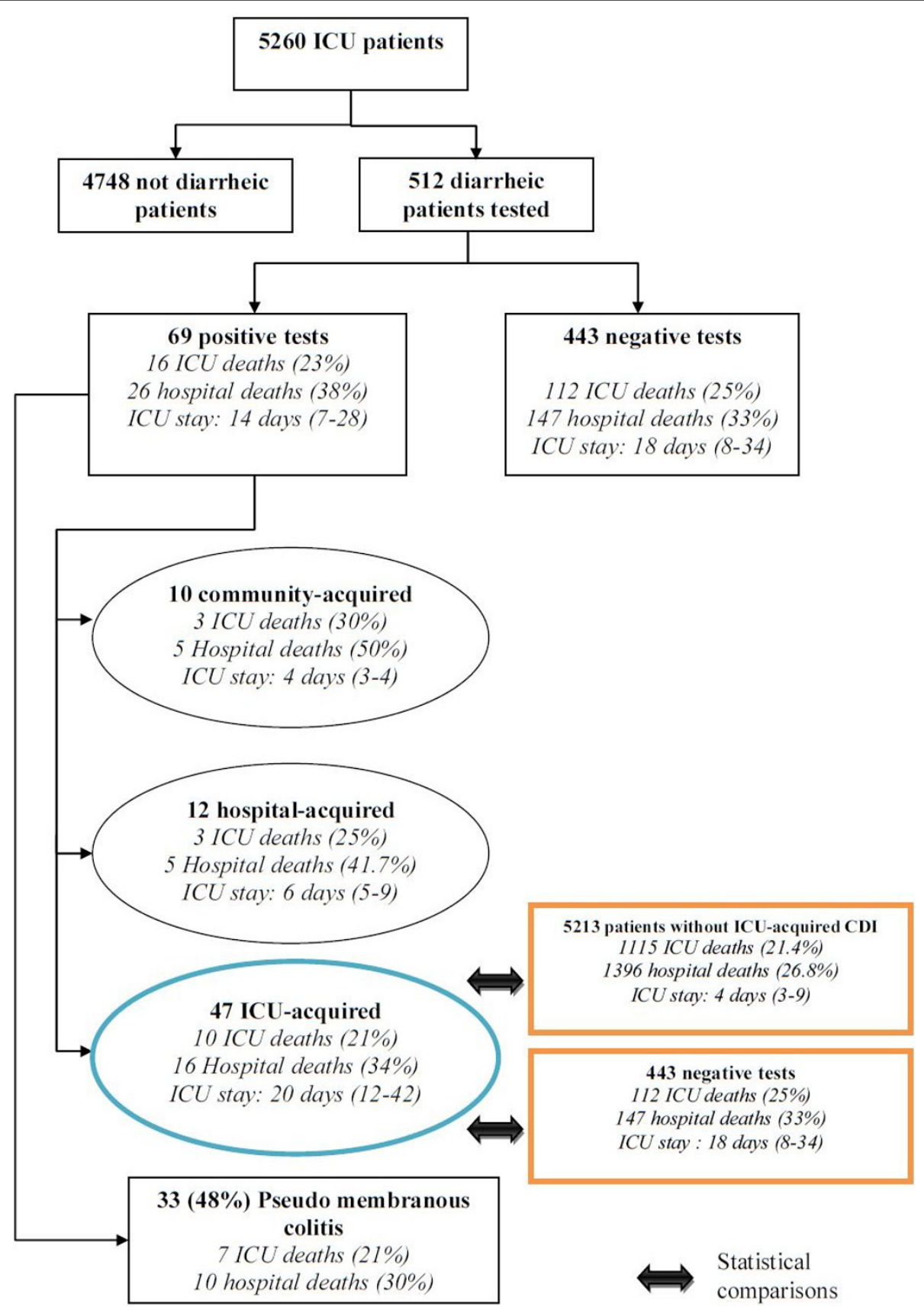

Figure 1 Flow chart of patients.

with increased mortality, regardless of the control groups, and after careful adjustment on confounding factors of mortality and on other adverse events and nosocomial infections associated with mortality.

The crude mortality rate associated with ICU-acquired $\mathrm{CDI}$ that we observed is similar to that observed in previous studies conducted elsewhere [7,8,21-23]. It is also notable that, even if the duration of ICU stay of CDI patients was considerably longer than that of other mechanically ventilated patients, the extra-length of stay that we estimated using a multistate model was 6.3 days and did not reach a statistical significance $(P=0.14)$.

Treatment of CDI occurred after a median delay of one day after diagnostic test sampling. The early treatment of patients probably explains the lack of significant impact on mortality.

Our results are in contradiction with previous studies conducted in ICUs that have found a higher mortality of 
Table 1 Patients' characteristics.

\begin{tabular}{|c|c|c|c|}
\hline Characteristics & $\begin{array}{l}\text { Tested patients } \\
\quad(n=512)\end{array}$ & $\begin{array}{l}\text { Patients with ICU-acquired CDI } \\
(n=47)\end{array}$ & $\begin{array}{l}\text { Patients without ICU-acquired CDI } \\
\qquad(n=5,213)\end{array}$ \\
\hline Age & 67 (56 to 76$)$ & 63 (55 to 75$)$ & $64(51$ to 76$)$ \\
\hline Male & $315(61.5)$ & $29(61.7)$ & $3,172(60.9)$ \\
\hline \multicolumn{4}{|l|}{ Category of admission } \\
\hline Medicine & $384(75)$ & $38(80.9)$ & $4,076(78.2)$ \\
\hline Emergency surgery & $76(14.8)$ & $5(10.6)$ & $671(12.9)$ \\
\hline Scheduled surgery & $52(10.2)$ & $4(8.5)$ & $466(8.9)$ \\
\hline \multicolumn{4}{|l|}{ Main symptom at admission } \\
\hline Multiple organ failure & $22(4.3)$ & $2(4.3)$ & $135(2.6)$ \\
\hline Septic shock & $110(21.5)$ & $12(25.5)$ & $575(11.0)$ \\
\hline Hemorrhagic shock & $14(2.7)$ & $2(4.3)$ & $203(3.9)$ \\
\hline Cardiogenic shock & $19(3.7)$ & 0 & $201(3.9)$ \\
\hline Mixed or other shock & $11(2.1)$ & $1(2.1)$ & $114(2.2)$ \\
\hline Acute respiratory failure & $155(30.3)$ & $17(36.2)$ & 1,191 (22.9) \\
\hline Acute renal failure & $34(6.6)$ & 0 & $264(6.1)$ \\
\hline Coma & $64(12.5)$ & $7(14.9)$ & $956(18.3)$ \\
\hline \multicolumn{4}{|l|}{ Chronic illness } \\
\hline Hepatic & $40(7.8)$ & $7(14.9)$ & $326(6.3)$ \\
\hline Cardiovascular & $60(11.7)$ & $7(14.9)$ & $675(13.0)$ \\
\hline Pulmonary & $67(13.1)$ & $7(14.9)$ & $797(15.3)$ \\
\hline Renal & $20(3.9)$ & $5(10.6)$ & $304(5.8)$ \\
\hline Immunosuppression & $91(17.8)$ & $6(12.8)$ & $631(12.1)$ \\
\hline Diabetes mellitus & $57(11.1)$ & $7(14.9)$ & $782(15.0)$ \\
\hline LOD & $6(4$ to 8$)$ & 7 (5 to 9$)$ & 5 (3 to 7$)$ \\
\hline SOFA & $8(5.5$ to 11$)$ & 8 (6 to 12$)$ & $6(3$ to 9$)$ \\
\hline SAPS ॥ & 45 (36 to 59$)$ & 50 (39 to 63) & 39 (28 to 54$)$ \\
\hline Duration of Mechanical ventilation & 12 (3 to 26$)$ & 14(8 to 29$)$ & $1(0$ to 6$)$ \\
\hline Duration of Proton pump inhibitor & $12(5$ to 25$)$ & $15(9$ to 30$)$ & $3(0$ to 7$)$ \\
\hline \multicolumn{4}{|l|}{ McCabe score } \\
\hline Unplanned death in five years & $292(57)$ & $32(68.1)$ & $3,047(58.5)$ \\
\hline Planned death between one and five years & $184(35.9)$ & $12(25.5)$ & $1,697(32.6)$ \\
\hline Planned death in a year & $36(7)$ & $3(6.4)$ & $459(8.8)$ \\
\hline \multicolumn{4}{|l|}{ Prognosis } \\
\hline Death during ICU stay & $128(25)$ & $10(21.3)$ & $1,115(21.4)$ \\
\hline Death during hospital stay & $173(33.8)$ & $16(34)$ & $1,396(26.8)$ \\
\hline Duration of ICU stay & 17 (8 to 33.5 ) & 20 (12 to 42$)$ & 4 (3 to 9) \\
\hline Duration of hospital stay & 40 (23 to 67$)$ & 46 (28 to 78$)$ & 19 (9 to 36$)$ \\
\hline
\end{tabular}

Frequencies (percentage), Median (Q1 25\% to Q3 75\%). CDI: Clostridium difficile infection; LOD, Logistic Organ Dysfunction; SAPS, Simplified Acute Physiological Score; SOFA, Systemic Organ Failure Assessment;

patients with ICU-acquired CDI. Ang et al. found a higher crude ICU mortality of $33.9 \%$ in ICU acquired CDI as compared to other ICU patients (29\%) [7]. Using a matched case-control design, Kenneally et al. [8] found the overall 30-day mortality rate in a cohort of $278 \mathrm{ICU}$ patients with CDI equaled $36.7 \%$, giving a $6.1 \%(95 \% \mathrm{CI}$, $-1.7 \%$ to $13.9 \%, P=0.127$ ) CDI-attributable mortality rate. However, they did not adjust for confounding variables, such as severity of disease or other adverse events. Another study reported by Lawrence et al. [21] identified 40 ICU-acquired CDI in a 19-bed medical ICU during a 30-month period. Using univariate analysis, CDI neither influenced ICU- (CDI 18 vs. other 20\%) nor hospital mortality (CDI $30 \%$ vs. other 28\%), but was associated with an increase in the crude length of ICU- (CDI 15 days vs. other 3 days, $P<0.001$ ) and hospital stay (CDI 38 vs. other 10 days, $P<0.001)$. After adjustment for severity of the acute illness, vancomycin resistant enterococcus (VRE) colonization, receipt of antimicrobial and occurrence of nosocomial infection, but without taking into account ICU time before CDI acquisition, CDI was associated with a longer ICU length of stay (OR, 1.24 (95\% CI, 1.07 to 1.44)).

There are a number of potential reasons why studies have shown variable association with CDI and mortality. 
Table 2 Characteristics of ICU-acquired CDI patients

\begin{tabular}{|c|c|c|}
\hline Characteristics & & Values \\
\hline Age & & $63(55 ; 75)$ \\
\hline \multirow[t]{2}{*}{ Sex } & Female & $18(38.3)$ \\
\hline & Male & $29(61.7)$ \\
\hline \multirow[t]{2}{*}{ Immunocompromised } & No & $41(87.2)$ \\
\hline & Yes & $6(12.8)$ \\
\hline \multirow[t]{2}{*}{ Diabetes } & No & $40(85.1)$ \\
\hline & Yes & $7(14.9)$ \\
\hline \multirow[t]{2}{*}{ Renal chronic disease (Knaus) } & No & $42(89.4)$ \\
\hline & Yes & $5(10.6)$ \\
\hline \multirow[t]{2}{*}{ Cancer } & No & $46(97.9)$ \\
\hline & Yes & $1(2.1)$ \\
\hline \multirow[t]{3}{*}{ McCabe Score } & Unplanned death in five years & $32(68.1)$ \\
\hline & Planned death between one and five years & $12(25.5)$ \\
\hline & Planned death in a year & $3(6.4)$ \\
\hline \multirow[t]{2}{*}{ Pseudomenbranous colitis } & No & $23(48.9)$ \\
\hline & Yes & $24(51.1)$ \\
\hline Maximum $w_{b c} \$$ & & $13,660(10,100 ; 19,400)$ \\
\hline Maximum creat $^{5}$ & & $120(73 ; 206)$ \\
\hline Maximum temperature $\left({ }^{\circ} \mathrm{C}\right)$ & & $38.5(38 ; 38.8)$ \\
\hline Maxmimu Ht (\%) & & $28.5(27 ; 31.5)$ \\
\hline \multirow[t]{2}{*}{ Corticosteroids } & No & $30(63.8)$ \\
\hline & Yes & $17(36.2)$ \\
\hline \multirow[t]{2}{*}{ Enteral nutrition } & No & 15 (31.9) \\
\hline & Yes & $32(68.1)$ \\
\hline \multirow[t]{6}{*}{ CDI severity score ${ }^{f}$} & 2 & $1(2.1)$ \\
\hline & 3 & $7(14.9)$ \\
\hline & 4 & $14(29.8)$ \\
\hline & 5 & $14(29.8)$ \\
\hline & 6 & $7(14.9)$ \\
\hline & 7 & $4(8.5)$ \\
\hline SOFA score (CDI day) & & $5(3 ; 7)$ \\
\hline SOFA coagulation & & $0(0 ; 1)$ \\
\hline SOFA respiratory & & $1(1 ; 2)$ \\
\hline SOFA liver & & $0(0 ; 0)$ \\
\hline SOFA hemodynamic & & $1(0 ; 1)$ \\
\hline SOFA neurology & & $1(0 ; 3)$ \\
\hline SOFA kidney & & $0(0 ; 2)$ \\
\hline
\end{tabular}

$\$$, calculated on the day of CDI and two days before. $£$, one point each is given for an age of $>60$ years, a temperature of $>38.3 \mathrm{C}$, an albumin level of $<2.5$ $\mathrm{mg} / \mathrm{dL}$, and a WBC count of $>15,000$ cells $/ \mathrm{mm}^{3}$; two points each are given for the presence of pseudomembranous colitis and hospitalization in the intensive care unit. Severe disease is considered to be present if the patient has a severity score of $\geq 2$ points [28].

\section{Selection of CDI patients and controls}

First, the choice of control groups may influence findings, as this has been outlined in a number of epidemiological publications [22,23]. Our methodological approach was to minimize bias due to the characteristics of the control group by comparing patients with ICU-CDI, to patients with diarrhea not linked to $C$. difficile, and to the whole ICU population. Indeed, there is much potential selection bias that arises if we choose only patients with diarrhea as a control group. On the other hand, controls should be selected from the same source population or study base that gives rise to the cases. The patients whose stools have been sampled are possibly different from the ones that have not been sampled.

However, the variability of the patient populations might also explain the variability in the association between mortality and CDI disease in the patient populations under study. Our study population included all ICU patients, and was different from that of other studies that were interested in specific selected populations, such as older persons, ill patients or burn unit patients. 
Table 3 Multivariate analysis to estimate independent prognostic effect of ICU acquired CDI in ICU patients ( $n=$ 5,260)

\begin{tabular}{|c|c|c|}
\hline Parameter & $\mathrm{CSHR}_{\text {Death }}(95 \% \mathrm{Cl}) P$ & CSHR $_{\text {Discharge }}(95 \% \mathrm{Cl}) P$ \\
\hline \multicolumn{3}{|l|}{ Fixed variables at admission } \\
\hline Symptom of septic shock & 0.813 (0.68 to 9.77) $P=0.02$ & $0.82(0.73$ to 0.92$) P=0.0005$ \\
\hline Symptom of acute respiratory failure & $0.898(0.77$ to 1.04$) P=0.16$ & $0.61(0.57$ to 0.66$) P<.0001$ \\
\hline Presence of at least one chronic disease & $1.04(0.92$ to 1.19$) P=0.5$ & $0.91(0.85$ to 0.97$) P=0.005$ \\
\hline McCabe: death expected within five years & 1.57 (1.37 to 1.79$) \mathrm{P}<.0001$ & 0.89 (0.83 to 0.95$) P=0.001$ \\
\hline \multicolumn{3}{|l|}{ Fixed variables in the first 48 hours } \\
\hline Urinary bladder catheter & 0.506 (0.41 to 0.63$) P<.0001$ & 0.68 (0.62 to 0.74$) P<.0001$ \\
\hline Vasopressors & $1.317(1.13$ to 1.54$) P=0.0006$ & 0.80 (0.73 to 0.87$) P<.0001$ \\
\hline Central catheter & 0.944 (0.81 to 1.10$) P=0.5$ & 0.65 (0.60 to 0.70$) P<.0001$ \\
\hline Mechanical ventilation & $1.037(0.86$ to 1.25$) P=0.7$ & $0.70(0.65$ to 0.76$) P<.0001$ \\
\hline DNR order & 3.146 (2.72 to 3.64$) P<.0001$ & 0.56 (0.47 to 0.66) $P<.0001$ \\
\hline SAPS II : $\leq 36$ pts & $1 ; P<.0001$ & $1 ; P<.0001$ \\
\hline 37 to 45 & 1.90 (1.48 to 2.44$)$ & 0.81 (0.74 to 0.88$)$ \\
\hline 46 to 59 & 2.926 (2.30 to 3.72$)$ & 0.74 (0.68 to 0.82$)$ \\
\hline$\geq 60$ & 7.715 (6.09 to 9.77$)$ & $0.48(0.42$ to 0.55$)$ \\
\hline \multicolumn{3}{|l|}{ Time dependant variables } \\
\hline CRBSI & $1.67(1.12$ to 2.48$) P=0.01$ & $0.97(0.67$ to 1.41$) P=0.9$ \\
\hline Other BSI & $1.08(0.87$ to 1.35$) P=0.5$ & 0.45 (0.39 to 0.54$) P<.0001$ \\
\hline VAP without BSI & $1.00(0.82$ to 1.22$) P=1$ & $0.47(0.41$ to 0.54$) P<.0001$ \\
\hline Deep and organ/space surgical site infection without BSI & 0.79 (0.38 to 1.65$) P=0.5$ & $0.76(0.53$ to 1.09$) P=0.14$ \\
\hline Pneumothorax & $1.03(0.73$ to 1.47$) P=0.9$ & $0.47(0.35$ to 0.64$) P<.0001$ \\
\hline Gastrointestinal bleeding & $1.82(1.27$ to 2.61$) P=0.001$ & $0.79(0.54$ to 1.14$) P=0.21$ \\
\hline Severe hypernatremia & 1.67 (1.37 to 2.04$) P<.0001$ & $0.81(0.70$ to 0.94$) P=0.005$ \\
\hline CDI & $0.71(0.38$ to 1.35$) P=0.3$ & $0.74(0.52$ to 1.06$) P=0.097$ \\
\hline
\end{tabular}

BSI, Blood Stream Infection; CDI, Clostridium difficile infection; CRBSI, Catheter-Related Blood Stream Infection; CSHR (95\% Cl), Cause Specific Hazard Ratio and 95\% confidence interval; DNR, Do Not Resuscitate; SAPS, Simplified Acute Physiological Score. Other variables that were tested but not retained in the model were the following, at admission, age, sex, category of admission, AVC diagnosis, AIDS and corticosteroid use; in the first 48 hours, Proton Pump Inhibitor and SOFA. See Additional file 1 for details on univariate analysis. Time dependent variables were forced in the model.

Table 4 Multivariate analysis to estimate independent prognostic effect of ICU-acquired CDI in the tested diarrheic patients $(n=490)$

\begin{tabular}{|c|c|c|}
\hline Parameter & $\mathrm{CSHR}_{\text {Death }}(95 \% \mathrm{Cl}) P$ & CSHR $_{\text {Discharge }}(95 \% \mathrm{Cl}) P$ \\
\hline \multicolumn{3}{|l|}{ Fixed variables at admission } \\
\hline CVA diagnosis at admission & $3.94(1.55$ to 10.0$) P=0.004$ & 1.19 (0.61 to 2.32$) P=0.6$ \\
\hline Cardiac chronic disease (Knaus) & $1.78(1.09$ to 2.9$) P=0.02$ & $0.96(0.67$ to 1.38$) P=0.8$ \\
\hline AIDS & $2.91(0.88$ to 9.67$) P=0.08$ & $0.87(0.35$ to 2.13$) P=0.8$ \\
\hline Corticosteroid use & $1.78(0.87$ to 3.65$) P=0.11$ & 0.67 (0.41 to 1.10$) P=0.12$ \\
\hline Death expected (McCabe) & $1.76(1.2$ to 2.59$) P=0.004$ & $1.04(0.84$ to 1.30$) P=0.7$ \\
\hline \multicolumn{3}{|l|}{ Fixed variables in the first 48 hours } \\
\hline DNR Order & 3.01 (1.74 to 5.22$) P<.0001$ & $0.77(0.47$ to 1.27$) P=0.3$ \\
\hline \multicolumn{3}{|l|}{ Variable the days before test } \\
\hline SOFA the days before $C D$ test & 1.15 (1.09 to 1.22$) P<.0001$ & 0.90 (0.87 to 0.93$) P<.0001$ \\
\hline \multicolumn{3}{|l|}{ Variable on the day of the test } \\
\hline CDI & $0.81(0.40$ to 1.64$) P=0.6$ & $0.70(0.5$ to 1.01$) P=0.06$ \\
\hline
\end{tabular}

AIDS, Acquired Immune Deficiency Syndrome; BSI, Blood Stream Infection; CDI, Clostridium difficile infection; CRBSI, Catheter Related Blood Stream Infection; DNR, Do Not Resuscitate; CSHR $(95 \% \mathrm{Cl})$, Cause Specific Hazard ratio and $95 \%$ confidence interval; CVA, Cerebrovascular accident; SAPS, Simplified Acute Physiological Score; SOFA, Sequential Organ Failure Assessment. Other variables that were tested but not retained in the model were the following: at admission, age, sex, category of admission, symptom of septic shock, symptom of acute respiratory failure, hepatic chronic disease, pulmonary chronic disease, renal chronic disease, immunosuppressive chronic disease, diabetes mellitus, presence of at least one chronic disease, AIDS, and corticosteroid use; in the first 48 hours - vasopressors, central catheter, urinary tract, mechanical ventilation, Proton Pump Inhibitor, SOFA and SAPS II. See Additional file 1 for details on univariate analysis. 
Finally, our epidemiological situation is different from North America's, as none of our patients had been infected with NAP1/O27 isolates. As this strain seems to be more virulent comparatively to others, our lower mortality rate could be explained by this microbiological difference. Indeed, in recent years with the emergence of a hypervirulent strain, the annual frequency of and the case fatality due to CDI have doubled in the United States $[2,24,25]$. Moreover, authors [1] demonstrated a higher mortality rate among inpatients in which nosocomial CDI developed compared to control subjects without CDI, matched for sex, age and disease severity; but this attributable mortality was measured during the CDI epidemic in Quebec caused by the hypervirulent strain NAP1/O27. Finally, the antimicrobial treatment was instituted early in CDI patients and may have decreased the impact of CDI on mortality and length of stay.

\section{Adjustment on confounders}

A second consideration that may explain differences in findings among studies conducted to date is in the analysis with adequate adjustment for confounding variables and competing events for mortality. Failure to adequately adjust for factors differently distributed among patients with or without CDI that also affect their outcome may lead to different conclusions. A number of factors could explain mortality in the ICU, such as advanced age and severity of illness at onset, and the presence of sepsis or septic shock. We used a modern statistical model that is frequently applied in other medical fields, such as cancer epidemiology. This approach is based on event histories, model time-to-event and may focus on time-dependent risk factors, such as nosocomial infections. Modern statistical methods are further able to simultaneously analyze different endpoint types, and they explicitly account for the timing of events [16]. Indeed, a case-control study could have led to different findings. It is important to underline that nosocomial infection is a time-dependent event. Occurrence of nosocomial infection is a timedynamic process, and the discharge acts as a competing risk when estimating the relationship between nosocomial infection and death. Both factors may bias the attributable mortality estimate. Matching patients with and without CDI infection on ICU duration and then performing conditional logistic regression is a widely used method to evaluate nosocomial infection (CDI here). The attributable mortality method is also used for other events that are dependent on the duration of exposure to a risk factor. With this method, each patient is classified as being exposed to CDI or unexposed (no CDI). In exposed patients, the data are handled as if the exposure was present at the study initiation (although exposure status is determined at study completion). Thus, the excess risk of death associated with the exposure is assumed to be present throughout the ICU stay, that is, both before and after the occurrence of the exposure. In other words, the exposure is handled as a time-independent variable. If the exposure is actually time-dependent, then a bias is introduced. Therefore, the impact of a time-dependent exposure on mortality is overestimated with this method. Our statistical model, in contrast, considers that the excess risk of death associated with the exposure exists only after the exposure onset. In this multistate model, each patient goes through two or more states. Thus, at study initiation, all patients are classified as being in the unexposed state. Over time, some patients acquire the exposure of interest (here, CDI); therefore switching to the exposed state, at different time points during the ICU stay. Eventually, the model fits reality far more closely than does the matched cohort design, resulting in the narrowest confidence intervals. The main advantage of using the multistate model for complete data is that mortality can be estimated over time. Therefore, the changes in the mortality rate over time can be detected.

We previously showed that about a quarter of ICU patients experienced more than one adverse event, and that nosocomial infections, such as ventilator-associated pneumonia, ICU-acquired bloodstream infections, deep and organ/space surgical site infection without BSI, and adverse events, such as pneumothorax, gastrointestinal bleeding [18] and hypernatremia [17], were independently associated with mortality. The multistate model we used allows us to avoid the estimation bias associated to these events $[16,26]$.

\section{Information bias}

Procedure for $C$. difficile detection is clearly defined in all study centers, and is only used in cases of watery stools. The toxin assay we used possesses an excellent specificity, but an $80 \%$ sensitivity [27]. It is, therefore, possible that some patients may have been falsely classified as belonging to the diarrheic CDI-negative control group, and thus decreased the study power (that is, the probability to find a difference if it exists). However, in the diarrheic CDI negative patients, no instance of hospital-acquired CDI was diagnosed after ICU discharge. Finally, our study was conducted in three French ICUs (in Grenoble and the Paris region), so our results cannot be extrapolated to the whole of France.

\section{Conclusions}

This study was conducted using a large database of ICU patients in a country where hypervirulent strains are rare. After careful adjustment for confounding variables, $\mathrm{CDI}$ is not associated with significant attributable mortality and extra length of stay. 


\section{Key messages}

- If treated promptly, ICU-acquired CDI is not independently associated with an increased mortality, and impacts marginally the ICU-length of stay.

- Careful adjustment on confounding factors of mortality and on other adverse events is instrumental to analyzing outcomes of ICU-acquired infections.

\section{Additional material}

Additional file 1: Univariate factors associated with prognosis in ICU patient and diarrheic patients tested. Tables with variables associated with death or discharge by univariate analysis in ICU patients and diarrheic patients tested.

\section{Abbreviations}

BSI: bloodstream infection during ICU stay; CDI: Clostridium difficile infection CSHR: cause specific hazard ratio; D: Death; DC: Discharge; HR: hazard ratio; LOD: logistic organ dysfunction; SAPS: simplified acute physiologic score; SOFA: sequential organ failure assessment; VAP: ventilator-associated pneumonia; VRE: vancomycin resistant enterococcus.

\section{Author details}

'INSERM U823; University Grenoble 1 - Albert Bonniot Institute, Rond-point de la Chantourne, Grenoble, 38042, France. ${ }^{2}$ Microbiology and Infection Control Unit, Necker Teaching Hospital, 145 rue de sèvres, Paris 75015, France. ${ }^{3}$ Medical-Surgical ICU, Delafontaine Hospital, 2 rue du docteur Delafontaine, Saint-Denis, 93205, France. ${ }^{4}$ ICU, Saint Joseph Hospital, 185 Rue Raymond Losserand, Paris, 75014, France. ${ }^{5}$ Medical ICU, Albert Michallon Teaching Hospital, Boulevard de la Chantourne, Grenoble, 38043, France. ${ }^{6}$ Critical Care Medicine, Peter Lougheed Centre and University of Calgary, 26th Street NE, Calgary, AB T1Y 6J4, Canada. ${ }^{7}$ Microbiology department, André Mignot Hospital, 177 rue de Versailles, Le Chesnay, 78157, France. ${ }^{8}$ EA 4043, USC INRA, Paris-Sud 11 University, 5 Rue Jean Baptiste Clément, Châtenay Malabry, 92290, France.

\section{Authors' contributions}

JRZ, AV, AF and JFT conceived the study, designed the analysis and interpretation of the data, and drafted the manuscript. JFT, AV, AF, CS, CA, MGA, MNM and AT acquired data. CS, CA, MGA, MNM, AT, KL and ALM helped with acquisition of data, critical revision of the manuscript and final approval. All authors have read and approved the manuscript for publication.

\section{Competing interests}

The authors declare no competing interests.

Received: 9 May 2012 Revised: 15 October 2012

Accepted: 25 October 2012 Published: 5 November 2012

\section{References}

1. Pepin J, Valiquette $L$, Cossette B: Mortality attributable to nosocomial Clostridium difficile-associated disease during an epidemic caused by a hypervirulent strain in Quebec. CMAJ 2005, 173:1037-1042.

2. Zilberberg MD, Shorr AF, Kollef MH: Increase in adult Clostridium difficilerelated hospitalizations and case-fatality rate, United States, 2000-2005. Emerg Infect Dis 2008, 14:929-931.

3. Ramaswamy R, Grover H, Corpuz M, Daniels P, Pitchumoni CS: Prognostic criteria in Clostridium difficile colitis. Am J Gastroenterol 1996, 91:460-464.

4. Kyne L, Hamel MB, Polavaram R, Kelly CP: Health care costs and mortality associated with nosocomial diarrhea due to Clostridium difficile. Clin Infect Dis 2002, 34:346-353.

5. Pepin J, Valiquette L, Alary ME, Villemure P, Pelletier A, Forget K, Pépin K, Chouinard D: Clostridium difficile-associated diarrhea in a region of
Quebec from 1991 to 2003: a changing pattern of disease severity. CMAJ 2004, 171:466-472.

6. Bishara J, Peled N, Pitlik S, Samra Z: Mortality of patients with antibioticassociated diarrhoea: the impact of Clostridium difficile. J Hosp Infect 2008, 68:308-314.

7. Ang CW, Heyes G, Morrison P, Carr B: The acquisition and outcome of ICU-acquired Clostridium difficile infection in a single centre in the UK. $J$ Infect 2008, 57:435-440.

8. Kenneally C, Rosini JM, Skrupky LP, Doherty JA, Hollands JM, Martinez E, McKinzie WE, Murphy T, Smith JR, Micek ST, Kollef MH: Analysis of 30-day mortality for Clostridium difficile-associated disease in the ICU setting. Chest 2007, 132:418-424.

9. Lewis SJ, Heaton KW: Stool form scale as a useful guide to intestinal transit time. Scand J Gastroenterol 1997, 32:920-924.

10. Planche T, Aghaizu A, Holliman R, Riley P, Poloniecki J, Breathnach A, Krishna S: Diagnosis of Clostridium difficile infection by toxin detection kits: a systematic review. Lancet Infect Dis 2008, 8:777-784.

11. Le Gall JR, Lemeshow S, Saulnier F: A new Simplified Acute Physiology Score (SAPS II) based on a European/North American multicenter study. JAMA 1993, 270:2957-2963.

12. Timsit JF, Fosse JP, Troche G, De Lassence A, Alberti C, Garrouste-Orgeas M, Bornstain C, Adrie C, Cheval C, Chevret S, OUTCOMEREA Study Group, France: Calibration and discrimination of daily LOD score in predicting hospital mortality of critically ill patients, comparison with daily SOFA score. Crit Care Med 2002, 30:2003-2013.

13. Le Gall JR, Klar J, Lemeshow S, Saulnier F, Alberti C, Artigas A, Teres D: The Logistic Organ Dysfunction system. A new way to assess organ dysfunction in the intensive care unit. ICU Scoring Group. JAMA 1996, 276:802-810.

14. Vincent JL, Moreno R, Takala J, Willatts S, De Mendonça A, Bruining H, Reinhart CK, Suter PM, Thijs LG: The SOFA (Sepsis-related Organ Failure Assessment) score to describe organ dysfunction/failure. On behalf of the Working Group on Sepsis- Related Problems of the European Society of Intensive Care Medicine. Intensive Care Med 1996, 22:707-710.

15. Lau B, Cole SR, Gange SJ: Competing risk regression models for epidemiologic data. Am J Epidemiol 2009, 170:244-256.

16. Wolkewitz M, Beyersmann J, Gastmeier P, Schumacher M: Modeling the effect of time-dependent exposure on intensive care unit mortality. Intensive Care Med 2009, 35:826-832.

17. Darmon M, Timsit JF, Francais A, Nguile-Makao M, Adrie C, Cohen $Y$, Garrouste-Orgeas M, Goldgran-Toledano D, Dumenil AS, Jamali S, Cheval C, Allaouchiche B, Souweine B, Azoulay E: Association between hypernatraemia acquired in the ICU and mortality: a cohort study. Nephrol Dial Transplant 2010, 25:2510-2515.

18. Garrouste Orgeas M, Timsit JF, Soufir L, Tafflet M, Adrie C, Philippart F, Zahar JR, Clec'h C, Goldran-Toledano D, Jamali S, Dumenil AS, Azoulay E, Carlet J, Outcomerea Study Group: Impact of adverse events on outcomes in intensive care unit patients. Crit Care Med 2008, 36:2041-2047.

19. Beyersmann J, Gastmeier P, Grundmann H, Bärwolff S, Geffers C, Behnke M, Rüden H, Schumacher M: Use of multistate models to assess prolongation of intensive care unit stay due to nosocomial infection. Infect Control Hosp Epidemiol 2006, 27:493-499.

20. Latouche A, Porcher R, Chevret S: Sample size formula for proportional hazards modelling of competing risks. Stat Med 2004, 23:3263-3274.

21. Lawrence SJ, Puzniak LA, Shadel BN, Gillespie KN, Kollef MH, Mundy LM: Clostridium difficile in the intensive care unit: epidemiology, costs, and colonization pressure. Infect Control Hosp Epidemiol 2007, 28:123-130.

22. Harris AD, Samore MH, Carmeli Y: Control group selection is an important but neglected issue in studies of antibiotic resistance. Ann Intern Med 2000, 133:159

23. Wacholder S, Silverman DT, McLaughlin JK, Mandel JS: Selection of controls in case-control studies. II. Types of controls. Am J Epidemiol 1992, 135:1029-1041.

24. McDonald LC, Killgore GE, Thompson A, Owens RC Jr, Kazakova SV Sambol SP, Johnson S, Gerding DN: An epidemic, toxin gene-variant strain of Clostridium difficile. N Engl J Med 2005, 353:2433-2441.

25. McDonald LC, Owings M, Jernigan DB: Clostridium difficile infection in patients discharged from US short-stay hospitals, 1996-2003. Emerg Infect Dis 2006, 12:409-415. 
26. Timsit JF, Zahar JR, Chevret S: Attributable mortality of ventilatorassociated pneumonia. Curr Opin Crit Care 2011, 17:464-471.

27. Crobach MJ, Dekkers OM, Wilcox MH, Kuijper EJ: European Society of Clinical Microbiology and Infectious Diseases (ESCMID): data review and recommendations for diagnosing Clostridium difficile-infection (CDI). Clin Microbiol Infect 2009, 15:1053-1066.

28. Gerding DN, Muto CA, Owens RC Jr: Treatment of Clostridium difficile infection. Clin Infect Dis 2008, 46(Suppl 1):S32-42.

doi:10.1186/cc11852

Cite this article as: Zahar et al:: Outcome of ICU patients with Clostridium difficile infection. Critical Care 2012 16:R215.

Submit your next manuscript to BioMed Central and take full advantage of:

- Convenient online submission

- Thorough peer review

- No space constraints or color figure charges

- Immediate publication on acceptance

- Inclusion in PubMed, CAS, Scopus and Google Scholar

- Research which is freely available for redistribution

Submit your manuscript at www.biomedcentral.com/submit
() Biomed Central 